\title{
THE PRODUCTION OF FLAME RETARDANT PAPER WITH DOPO
}

\author{
Hatice Birtane iD \\ Marmara University, Faculty of Arts and Sciences, Department of Chemistry, Istanbul, Turkey
}

\begin{abstract}
Flame retardant property to paper increases the use of paper and the value of paper products. The flame retardant property was achieved by the addition of an organophosphorus agent to the paper. A great deal of research has been done on 9,10-Dihydro-9-oxa-10-phosphaphenanthrene-10-oxide (DOPO) derivatives as flame retardants. To apply the flame retardant property in condensed phase, DOPO derivative materials are generally used as an acid source for intumescent flame retardants to promote dehydration and carbonization of the charring agent to form a continuous layer of carbon. In this study, In order to prepare a flame retardant paper coating, DOPO derivative was synthesized with 3-aminophenyl sulfone, and benzaldehyde reaction and the chemical structure of DOPO is illuminated by ATR-FTIR then paper was coating with a flame retardant coating formulation ingredient with DOPO. The paper's properties were investigated. Surface energy of coated papers and contact angles were determined with goniometer. Printability parameters such as color, gloss, surface tension were examined. The results the study DOPO added paper coatings improve the paper flame retardancy.
\end{abstract}

Key words: Flame retardant, Coating, DOPO, Printability

\section{INTRODUCTION}

Flame retardant materials represented to provide fire resistance to prevent or suppress the combustion process or to allow slow combustion in materials (Bernava and Strazds, 2015) were rare and required special handling methods. In the past, halogenated flame retardants have been widely applied to improve the flame retardancy of the coated material. These compounds have been limited due to the potential health and environmental hazards associated with the use of these compounds (Velencoso et al, 2018; Wang et al, 2019). Therefore, recently halogen-free flame retardants have been used as an alternative to halogenated flame retardants. Halogen-free flame retardants are phosphorus- (Wang et al, 2019; Wang et al, 2018; Zhang et al, 2017), nitrogen- (Wang et al, 2019; Huang et al, 2017), silicon- (Wang et al, 2019; Zhang et al, 2011; Liu et al, 2016) based compounds and nano flame retardants (Wang et al, 2019; Shabestari et al, 2017; Zhou et al, 2018; Qiu et al, 2017; Zhang et al, 2018; Vahabi et al, 2018).

Flame-retardant coatings prevent or delay the ignition of valuable documents (checks, money, valuable books) or printed papers (wallpapers, laminate parks, etc.) by providing an extinguishing time or prevent the spread of fire. (checks, money, valuable books) or printed papers (wallpapers, laminate parks, etc.) to provide an extinguishing time or prevent the spread of fire (Arman Kandırmaz, 2020).

In this study, it is aimed to obtain a flame reterdant coating and to examine the flame reterdancy performance of the coating. In this context, DOPO derivative was synthesized with 3-aminophenyl sulfone, and benzaldehyde reaction. In addition, there are trimethylolpropane triacrylate (TMPTA), 2Hydroxyethyl methacrylate (HEMA) and Poly(ethylene glycol) diacrylate (PEGDA) in the coating formulation. The synthesized DOPO derivative in certain proportions was added into the formulation and paper was coating.

\section{MATERIALS AND METHODS}

\subsection{Materials}

Trimethylolpropane triacrylate (TMPTA), 2-hydroxyethyl methacrylate (HEMA), poly(ethylene glycol) diacrylate (PEGDA), benzaldehyde, 3-aminophenyl sulfone and tetrahydrofuran were all purchased from Sigma Aldrich. 9,10-dihydro-9-oxa-10-phosphaphenanthrene-10-oxide (DOPO) and Darocur 1173 were obtained from Ciba Specialty Chemicals. 


\subsection{Synthesis of DOPO containing compounnd}

DOPO containing compound, as Ai et al. (Ai et al, 2019) suggested, prepared. The compounds DOPO $(13,78 \mathrm{~g}, 64 \mathrm{mmol}), 3$-aminophenyl sulfone $(7.95 \mathrm{~g}, 0.032 \mathrm{~mol})$, and benzaldehyde $(6.79 \mathrm{~g}, 64 \mathrm{mmol})$ were dissolved in tetrahydrofuran $(120 \mathrm{~mL})$. The mixture was stirred at $30{ }^{\circ} \mathrm{C}$ for 24 hours under a $\mathrm{N}_{2}$ atmosphere. The mixture was filtered and then white product was obtained. Subsequently, the crude product was added to a tetrahydrofuran solution and stirred; the solid was filtered and then precipitate was washed repeatedly with tetrahydrofuran. The synthesis scheme of the DOPO-derivate compound is given in Figure 1.
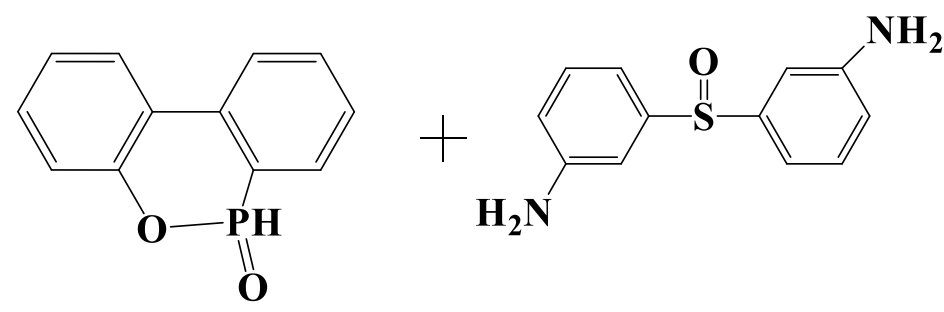<smiles>O=Cc1ccccc1</smiles>

\section{THF}

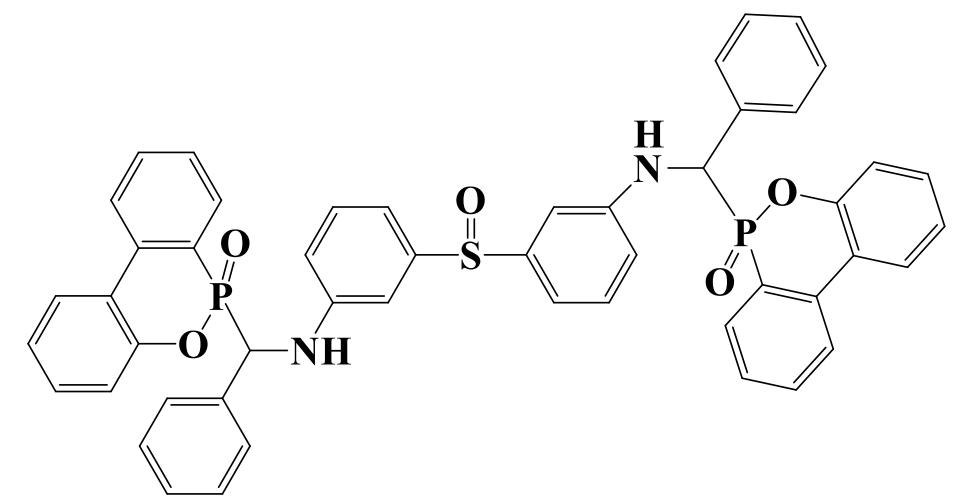

DOPO containing compound

Figure 1: Synthesis of DOPO containing compound

\subsection{Preparation of paper coating}

The base formulation is composed of trimethylolpropane triacrylate (TMPTA), 2-hydroxyethyl methacrylate (HEMA) and poly(ethylene glycol) diacrylate (PEGDA). The synthesized DOPO derivative in $1 \%, 3 \%$ and $\% 5$ proportions was added into the formulation and paper was coating. And then the coated papers were cured under UV-irridation. The formulation of coatings is given in Table 1. 


\begin{tabular}{|c|c|c|c|c|c|}
\hline & $\begin{array}{c}\text { PEGDA } \\
(\%)\end{array}$ & $\begin{array}{c}\text { TMPTA } \\
(\%)\end{array}$ & $\begin{array}{c}\text { HEMA } \\
(\%)\end{array}$ & $\begin{array}{c}\text { Daracure } \\
1137 \\
(\%)\end{array}$ & $\begin{array}{c}\text { DOPO } \\
(\%)\end{array}$ \\
\hline FO & 20 & 60 & 18 & 3 & 0 \\
\hline F1 & 20 & 60 & 18 & 3 & 1 \\
\hline F3 & 20 & 60 & 18 & 3 & 3 \\
\hline F5 & 20 & 60 & 18 & 3 & 5 \\
\hline
\end{tabular}

\subsection{Characterization}

\subsubsection{ATR-FTIR}

The chemical composition and functional groups, of paper and coated papers that we prepared, were made by Perkin Elmer Spectrum100 ATR-FTIR in the wavelength range $4000-400 \mathrm{~cm}^{-1}$.

\subsubsection{Contact angle}

The wettability characteristics of the coatings were determined on a Kruss (Easy DropbDSA-2) tensiometer. The contact angles $(\theta)$ were measured by means of sessile drop test method in which drops were created by using a syringe. Measurements were made using 3-5 $\mu$ d drops of distilled water. For each sample, at least five measurements were made, and the average was taken.

\subsubsection{TGA}

The thermal stability of the paper, base formulation coated paper and DOPO containing coated papers was determined in the temperature range of 30 to $750{ }^{\circ} \mathrm{C}$ at a heating rate of $10{ }^{\circ} \mathrm{C} / \mathrm{min}$ under a nitrogen atmosphere (TGA, Pyris America).

\subsubsection{LOI measurements}

The flammability characteristics of the paper coatings were determined by the LOI test. The LOI values of the coating materials were measured by using a FTT (Fire Testing Technology) type instrument, on the test specimen bar of $120 \times 10 \times 3 \mathrm{~mm}$ according to ASTM D2863.

\section{RESULTS AND DISCUSSIONS}

\subsection{Characterization of coatings}

\subsubsection{ATR-FTIR}

DOPO containing paper coatings were characterized via FTIR spectroscopy and TGA. The FTIR spectra of paper, F0, F1, F3 and F5 are given in Figure 2. The bands at 1637 and $1581 \mathrm{~cm}^{-1}$ in FTIR spectra of F1, F3 and F5 are due to -P-Ph stretching vibrations (Oktay and Çakmakçı, 2017). The peak at $1155 \mathrm{~cm}^{-1}$ is attributed to the $-\mathrm{P}=\mathrm{O}$ stretching (Oktay and Çakmakçı, 2017).- $\mathrm{S}=\mathrm{O}$ peak is shown at $1405 \mathrm{~cm}^{-1}$. 


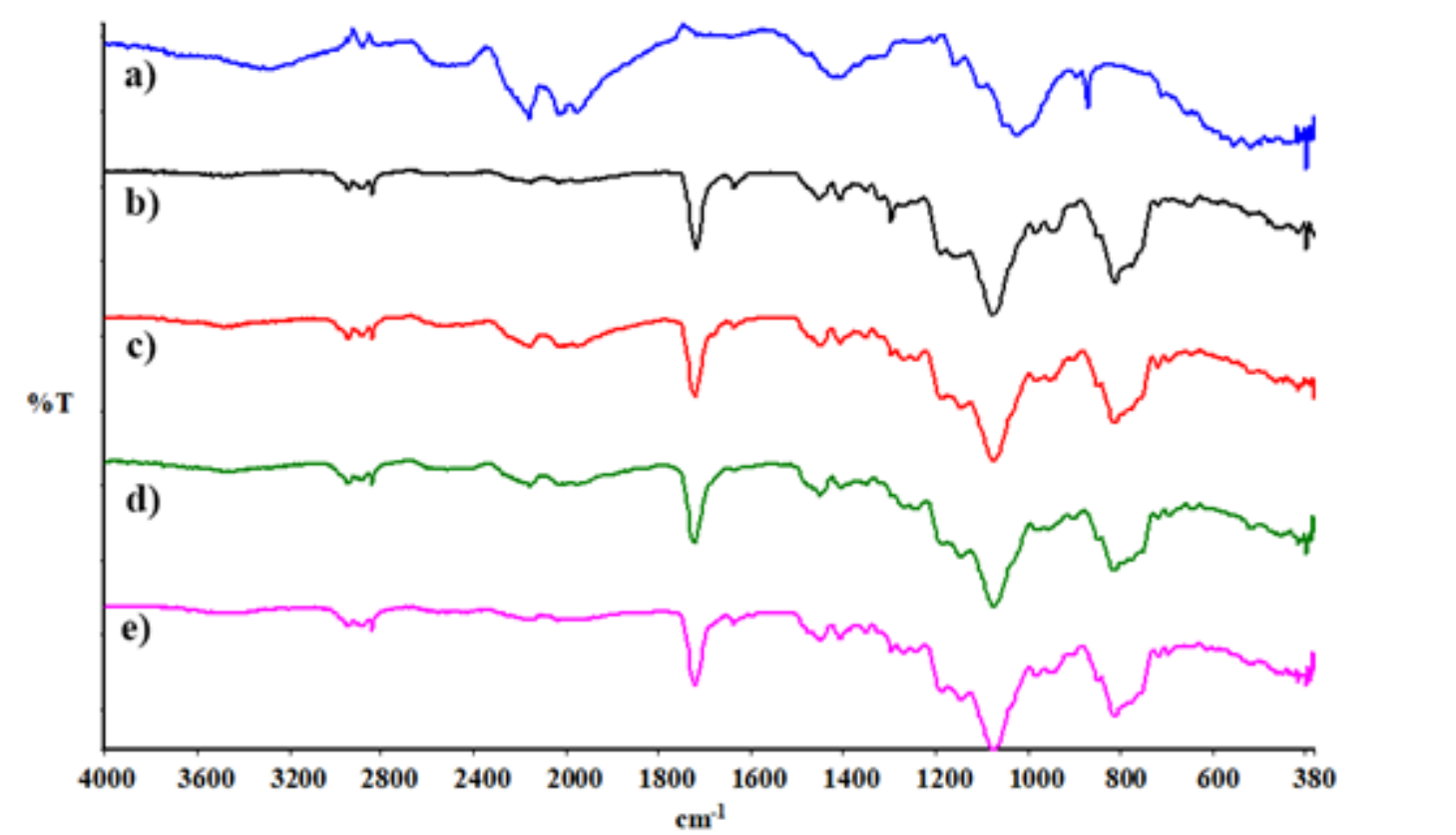

Figure 2: ATR-FTIR spectra of a) uncoated paper b) coated paper without DOPO compound c) coating with 1\% DOPO compound d) coating with 3\% DOPO compound e) coating with 5\% DOPO compound

FTIR results showed that DOPO containing paper coatings were prepared successfully.

\subsubsection{Thermal stability of coated papers}

The thermal stability of uncoated paper and paper coatings were evaluated with TGA under nitrogen atmosphere. Fig. 4 shows TGA thermograms of paper, F1, F3 and F5 formulations. Under nitrogen atmosphere, with the increased DOPO containing compound percentage, $T_{5}$ and $T_{\max }$ were increased. The maximum weight loss temperatures and the residual masses increased with increasing amount of DOPO containing compound. From this results its concluded that the addition of DOPO containing compound improved the thermostability of coated papers. In previous reports, it was also shown that the thermal stability improves when DOPO containing compound is incorporated into paper coatings.

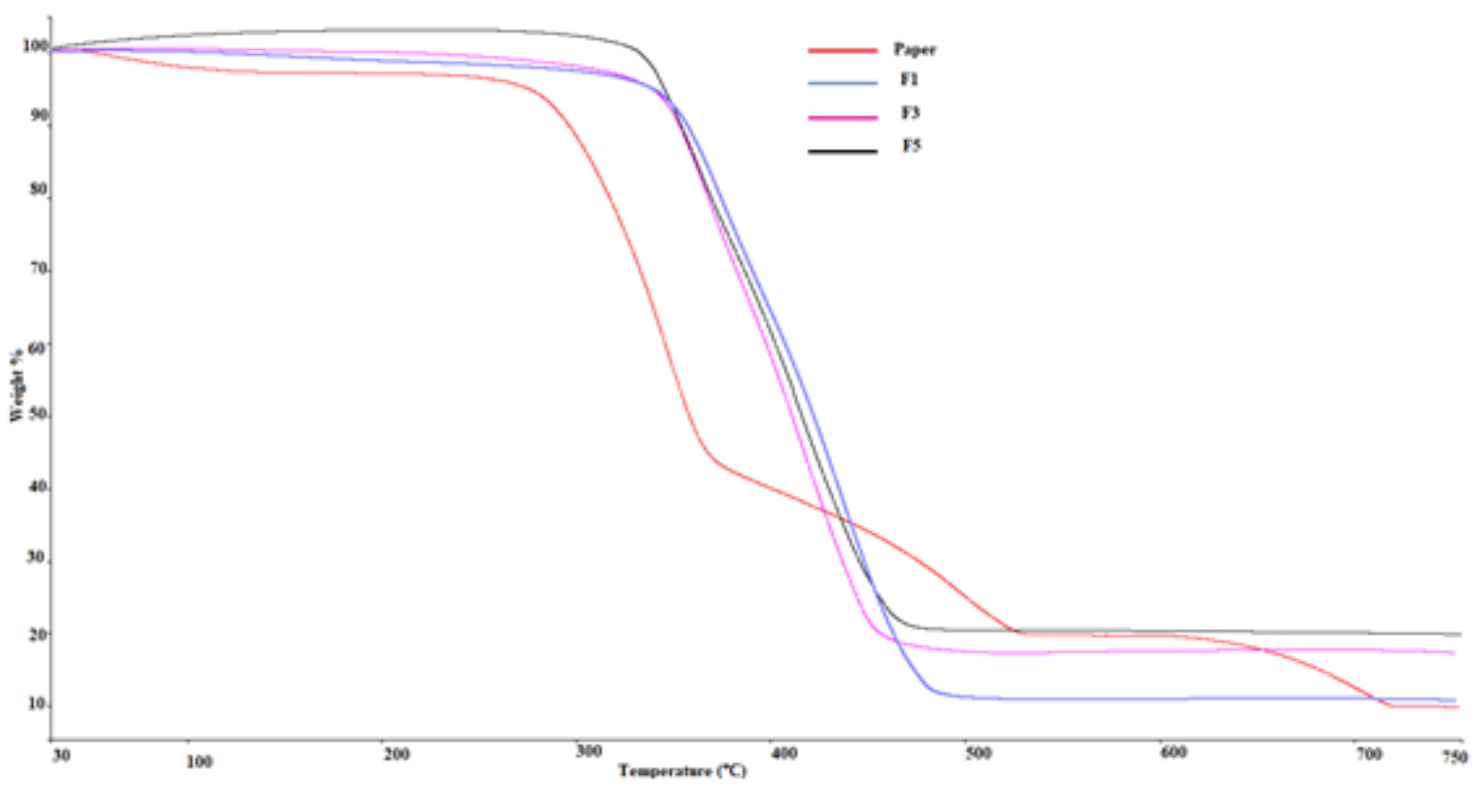

Figure 4: Thermogravimetric analysis of paper coatings 


\subsubsection{Wettability feature}

The contact angle values of all coatings are given in Table 2 . The water contact angle of paper without any coating was measured as $82^{\circ}$. When $3 \%$ DOPO containing was added to coating formulation (F3), the contact angle decreased to 34.9. On the other hand, the contact angle value of the DOPO containing papers descreased, this is due to the presence the hydrophilic groups in DOPO containing compound.

Table 2: Total surface energy and Contact Angle values of films

\begin{tabular}{|c|c|c|}
\hline Formulation Name & $\begin{array}{c}\text { Surface Energy } \\
\left(\mathrm{mJ} / \mathrm{m}^{2}\right)\end{array}$ & Contact Angle \\
\hline Uncoated paper & 35.4 & 82.0 \\
\hline F0 & 35.6 & 81.4 \\
\hline F1 & 40.1 & 69.1 \\
\hline F3 & 52.4 & 34.9 \\
\hline F5 & 58.0 & 19.4 \\
\hline
\end{tabular}

\subsubsection{Color and gloss properties of coatings}

The color values of the coated and uncoated papers are given in Table 3. Color differences were calculated by delta $E$ of substrates (F0, F1, F3, F5) how it differs from based paper. When the table is examined, the most changing parameter of the color is $\mathrm{L}$. This shows that the lightness has become darker, not the color. In other words, the color of the paper has not changed much, only the lightness of the color has changed. When the color differences are examined, the color difference caused by the change in the $L$ value is too high. However, the difference is not much in the visual inspection. When the gloss value was examined, it was determined that all coatings were very glossy compared to the base paper. Because the polymeric coating formulation filled the voids on the paper surface and reduced the diffuse reflection. Thus, the smooth reflection and gloss increased. However, with the addition of DOPO to the formulation, the roughness increased a little, so the gloss decreased. However, it still has a glossy surface than base paper. The gloss decreased as the amount of DOPO increased.

Table 3: Color and gloss properties of coatings

\begin{tabular}{|c|c|c|c|c|c|c|}
\hline Formulation No & $\mathrm{L}^{*}$ & $\mathrm{a}^{*}$ & $\mathrm{~b}^{*}$ & Image (acid) & $\Delta \mathrm{E}_{00}$ & Gloss \\
\hline Base paper & 80 & 0 & -3 & & Ref. & 6 \\
\hline F0 & 74 & -1 & -4 & & 4.59 & 28 \\
\hline F1 & 72 & -2 & -5 & & 6.58 & 26 \\
\hline F3 & 67 & -3 & -1 & & 10.67 & 22 \\
\hline F5 & 65 & -5 & 1 & & 13.54 & 20 \\
\hline
\end{tabular}




\subsubsection{Flame retardancy properties}

The flame retardancy properties of DOPO containing paper coatings were examined with LOI measurements. LOI values of coated and uncoated papers are given in figure 5. As can be seen from figure 5, when the LOI results are examined, it is seen that all the coatings on the base paper increase the $\mathrm{LOI}$ and make it difficult for the paper to ignite. However, this increase was effectively increased with the addition of DOPO to the coating formulation. In other words, it is more difficult to ignite in coatings with DOPO added. In addition, as the amount of DOPO increases, the LOI value increases slightly. Compared to the base paper, the F5 coating that gives the best LOI result, the LOI value increases by $30.2 \%$.

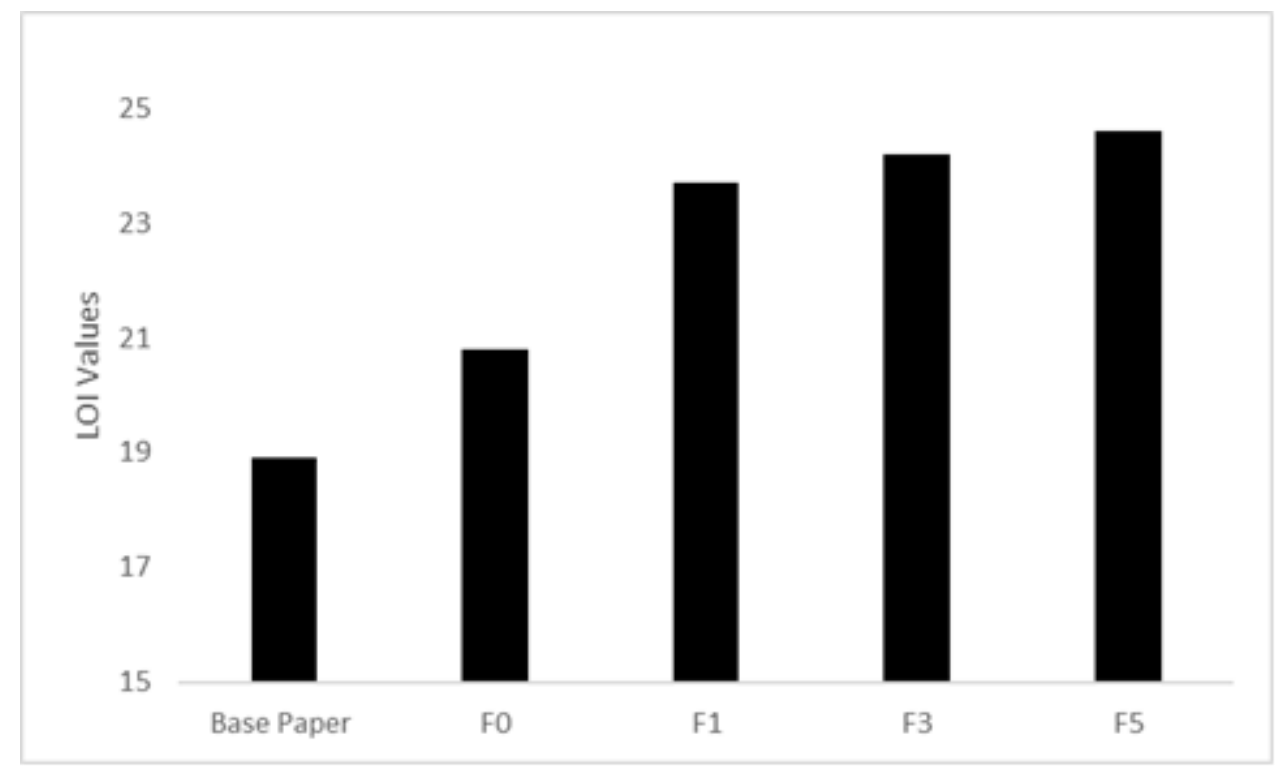

Figure 5: LOI values of coatings

\section{CONCLUSIONS}

According to ATR-FTIR results DOPO containing paper coatings were prepared successfully and DOPO coating paper has been given flame reterdancy property. TGA thermograms was also shown that the thermal stability improves when DOPO containing compound is incorporated into paper coatings.

When the results were examined, it was determined that DOPO increased the LOI value and made it difficult to ignite. According to the obtained LOI results, it is concluded that there will be more time to save printed products in a possible fire.

\section{REFERENCES}

[1] Ai, L., Yang, Z., Hu, J., Chen, S., Zeng, J., Liu, P.: "Synergistic Flame Retardant Effect of Organic Phosphorus-Nitrogen and Inorganic Boron Flame Retardant on Polyethylene", Polymer Engineering and Science 60, 414-422, 2020. doi: 10.1002/pen.25296.

[2] Arman Kandırmaz, E.: "Flame Retardant Hybrid Paper Coatings with PVA - Melamine / Zinc Borat" Journal of Graphic Engineering and Design 11 (1), 47-52, 2020. doi: 10.24867/JGED-2020-1-047.

[3] Bernava, A., Strazds, G.: "The Flame Retardant Coating of Linen Fabrics", Advanced Materials Research 1117, 219-222, 2015. doi: 10.4028/www.scientific.net/AMR.1117.219.

[4] Huang, H., Zhang, K., Jiang, J., Li, J., Liu, H.: "Highly dispersed melamine cyanurate flame-retardant epoxy resin composites", Polymer International 66, 85-91, 2017. doi: 10.1002/pi.5244.

[5] Liu, C., Chen, T., Yuan, C., Song, F., Chang, Chen, G., Xu, Y., Dai, L.: “Modification of epoxy resin through the self-assembly of a surfactant-like multielement flame retardant", Journal of Material Chemistry A 4, 3462-3470, 2016. doi: 10.1039/c5ta07115a.

[6] Oktay, B., Çakmakçı, E.: "DOPO tethered Diels Alder clickable reactive silica nanoparticles for bismaleimide containing flame retardant thiol-ene nanocomposite coatings", Polymer 131, 132-142, 2017. doi: 10.1016/j.polymer.2017.10.043 
[7] Qiu, S. L., Xing, W. Y., Feng, X. M., Yu, B., Mu, X. W., Yuen, R. K. K., Hu, Y.: "Self-standing cuprous oxide nanoparticles on silica@ polyphosphazene nanospheres: 3D nanostructure for enhancing the flame retardancy and toxic effluents elimination of epoxy resins via synergistic catalytic effect", Chemical Engineering Journal 309, 802-814, 2017. doi: 10.1016/j.cej.2016.10.100.

[8] Shabestari, M. E., Kalali, E. N., Gonzalez, V. J., Wang, D. Y., Fernandez Blazquez, J. P., Baselga, J., Martin, O.: "Effect of nitrogen and oxygen doped carbon nanotubes on flammability of epoxy nanocomposites", Carbon 121, 193-200, 2017. doi: 10.1016/j.carbon.2017.05.087.

[9] Vahabi, H., Saeb, M. R., Formela, K., Cuesta, M. L.: "Flame retardant epoxy/halloysite nanotubes nanocomposite coatings: exploring low-concentration threshold for flammability compared to expandable graphite as superior fire retardant", Progress in Organic Coating 119, 8-14, 2018. doi: 10.1016/j.porgcoat.2018.02.005.

[10] Velencoso, M. M., Battig, A., Markwart, J. C., Schartel, B., Wurm, F. R.: "Molecular firefighting-How modern phosphorus chemistry can help solve the flame retardancy task", Angewandte Chemie International Edition 130, 10608-10626, 2018. doi: 10.1002/anie.201711735.

[11] Wang, J., Ma, C., Wang, P., Qiu, S., Cai, W., Hu, Y.: "Ultra-low phosphorus loading to achieve the superior flame retardancy of epoxy resin", Polymer Degradation and Stability 149, 119-128, 2018. doi: 10.1016/j.polymdegradstab.2018.01.024.

[12] Wang, P., Chen, L., Xiao, H.: "Flame retardant effect and mechanism of a novel DOPO based tetrazole derivative on epoxy resin", Journal of Analytical and Applied Pyrolysis 139, 104-113, 2019. doi: 10.1016/j.jaap.2019.01.015.

[13] Zhang, C., Guo, X. D., Ma, S. M., Liu, X. R., Xu, J. Z., Ma, H. Y.: "Synthesis of an organicinorganic hybrid strontium hydroxystannate nanorod and application as novel flame retardant", Materials Letters 229, 297-300, 2018. doi: 10.1016/j.matlet.2018.07.047.

[14] Zhou, K. Q., Tang, G., Gao, R., Jiang, S. D.: "In situ growth of OD silica nanospheres on 2D molybdenum disulfide nanosheets: towards reducing fire hazards of epoxy resin", Journal of Hazardous Materials 344, 1078-1089, 2018. doi: 10.1016/j.jhazmat.2017.11.059.

[15] Zhang, W., Li, X., Yang, R.: "Pyrolysis and fire behaviour of epoxy resin composites based on a phosphorus-containing polyhedral oligomeric silsesquioxane (DOPO-POSS)", Polymer Degradation and Stability 96, 1821-1832, 2011. doi: 10.1016/j.polymdegradstab.2011.07.014.

[16] Zhang, Y., Yu, B., Wang, B., Liew, K. L., Song, L., Wang, C., Hu, Y.: "Highly effective P-P synergy of a novel DOPO-based flame retardant for epoxy resin", Industrial and Engineering Chemistry Research 56, 1245-1255, 2017. doi: 10.1021/acs.iecr.6b04292.

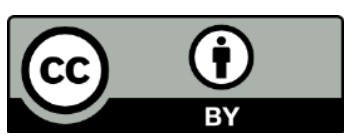

(C) 2020 Authors. Published by the University of Novi Sad, Faculty of Technical Sciences, Department of Graphic Engineering and Design. This article is an open access article distributed under the terms and conditions of the Creative Commons Attribution license 3.0 Serbia (http://creativecommons.org/licenses/by/3.0/rs/). 